\title{
Modernizing Monetary Policy Rules
}

FEDERAL RESERVE BANK of ST. LOUIS

\section{James Bullard}

President and CEO

Economic Club of Memphis

Oct. 18, 2018

Memphis, Tenn. 


\section{Introduction}




\section{Main ideas}

- Monetary policy rules have proven to be very useful in laying out benchmarks for monetary policy actions, both in academic papers and in practical policymaking.

- One popular rule has been Taylor (1999), which was constructed based on U.S. data from the 1980s and 1990s.*

- Since that time, three important macroeconomic developments have altered key elements of policy rule construction.

- Incorporating these developments yields a modernized policy rule that suggests the current level of the policy rate is about right over the forecast horizon.

*J.B. Taylor, "A Historical Analysis of Monetary Policy Rules," in Monetary Policy Rules, J.B. Taylor ed., University of Chicago Press, 1999, 319-48. 


\section{Monetary Policy Rules}




\section{A generic monetary policy rule}

- Monetary policy rules following the seminal paper by Taylor (1993) typically have the following form: ${ }^{*}$

$$
i_{t}=\rho i_{t-1}+(1-\rho)\left(r_{t}^{*}+\pi^{*}+\phi_{\pi} \pi_{t}^{G A P}+\phi_{y} y_{t}^{G A P}\right),
$$

where

$\bigcirc \quad i_{t}$ is the recommended value of the nominal policy rate;

○ $r_{t}^{*}=1$ is the natural real interest rate, also called "r-star";

$\bigcirc \pi^{*}=2$ denotes the FOMC's inflation target;

$\bigcirc \pi_{t}^{G A P}$ and $y_{t}^{G A P}$ denote the inflation gap and the output gap, respectively; and

$\bigcirc \phi_{\pi}=1.5, \phi_{y}=1$ and $\rho=0.85$ are parameters.

*J.B. Taylor, "Discretion versus policy rules in practice," Carnegie-Rochester Conference Series on Public Policy, December 1993, 39, 195-214. I will call the rule described here the "Taylor (1999)" rule, although details vary in the

literature. 


\section{Why use monetary policy rules?}

- Monetary policy rules are useful because they yield a recommended level for the policy rate as a function of current conditions in the economy.

- This helps set a baseline for the monetary policy debate. 


\section{What has changed since the 1980s?}

- There have been three widely discussed macroeconomic developments since the 1980s that affect the nature of monetary policy rules:

- First, the general level of short-term real interest rates has been trending lower for three decades; that is, $r_{t}{ }^{*}$ is smaller than it was.

- Second, the feedback from the real economy to inflation has attenuated by a factor of 10; that is, $\phi_{y}$ is smaller than it was.

- Third, the real-time measurement of inflation expectations has improved markedly in the U.S.; that is, $\pi_{t}^{G A P}$ can be measured more appropriately.

- In this talk, I will incorporate these factors into a modernized monetary policy rule and show the resulting policy rate recommendations. 


\section{Lower Short-Term Real Interest Rates}




\section{Lower short-term real interest rates}

- The Fed can influence short-maturity real interest rates through monetary policy.

- However, the Fed cannot control longer-term trends in real interest rates, which are affected by relatively slow-moving macroeconomic factors like demographics, productivity trends and the global demand for safe assets.

- Earlier this year, I discussed these factors in a talk and in a related published paper.* 


\section{Trends in real interest rates}

- The trend in short-term real interest rates has been decidedly lower over the last three decades.

- This enters the generic policy rule given earlier as the real interest rate term, the so-called "r-star."*

- One way to get a handle on this variable is to consider the nominal return on a one-year Treasury bill and subtract the trailing 12-month inflation rate.

- This gives a one-year ex-post safe real rate of return.

- Again, the Fed influences this return but does not control its trend.

* T. Laubach and J.C. Williams, "Measuring the Natural Rate of Interest," Review of Economics and Statistics, November 2003, 85(4), 1063-70. 


\section{The current low level of real rates}

- I will use a simple atheoretic method to choose an appropriate level for the short-term real rate to place in the modernized policy rule.

- I say "atheoretic" because I will not impose a theory on the level of this rate, but instead simply consider the trend that is evident in the current data.

- To draw the trend line, I will use the Hodrick-Prescott filter.

- According to this calculation, as shown in the next chart, the current trend value of the short-term real interest rate is about zero. 


\section{Trends in real interest rates}

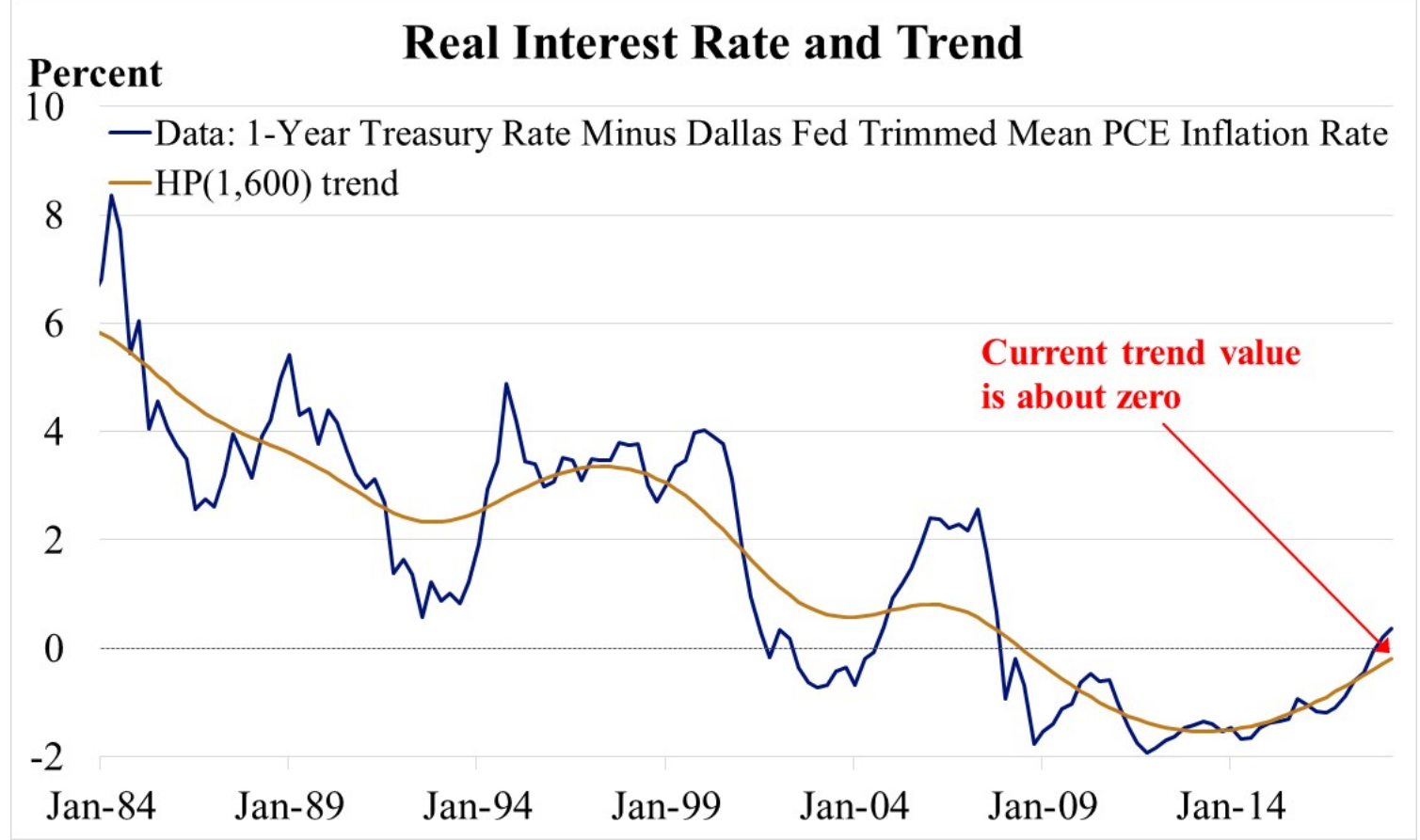

Sources: Federal Reserve Board, FRB of Dallas and author's calculations. Last observation: 2018-Q2. 


\section{One change to the policy rule}

- I will use the current HP-trend value of the short-term real interest rate as the value of $r_{t}{ }^{*}$ in the modernized policy rule, that is, $r_{t}{ }^{*}=0$.

- I will also assume that $r_{t}{ }^{*}$ will not change appreciably over the forecast horizon.

- This substitution gives one change to the Taylor (1999) policy rule that one would not have anticipated using data from the 1980s.

- There are at least two other important changes to make in order to more fully modernize the policy rule. 


\section{The Disappearing Phillips Curve}




\section{The disappearing Phillips curve}

- The feedback from the real economy to inflation has been called the Phillips curve.

- In the 1970s and 1980s, this feedback was relatively strong and formed the basis for the part of the monetary policy rule labeled as the output gap.

- However, this feedback has attenuated markedly since that time, to the point where arguably there is very little feedback at all.

- I discussed this lack of feedback earlier this year.* 


\section{International evidence}

- One way to see how the Phillips curve has changed is to consider a recent analysis by the Bank for International Settlements.

- They used rolling 15-year samples of data from G-7 economies and averaged across the results.

- The relationship used to be reliably negative: Lower unemployment led to higher inflation.

- But in recent years, the relationship has not been significantly different from zero.

- The following chart shows how the coefficient describing the strength of the feedback from the real economy to inflation has evolved over recent years. 


\section{Phillips curve slope in G-7 economies}

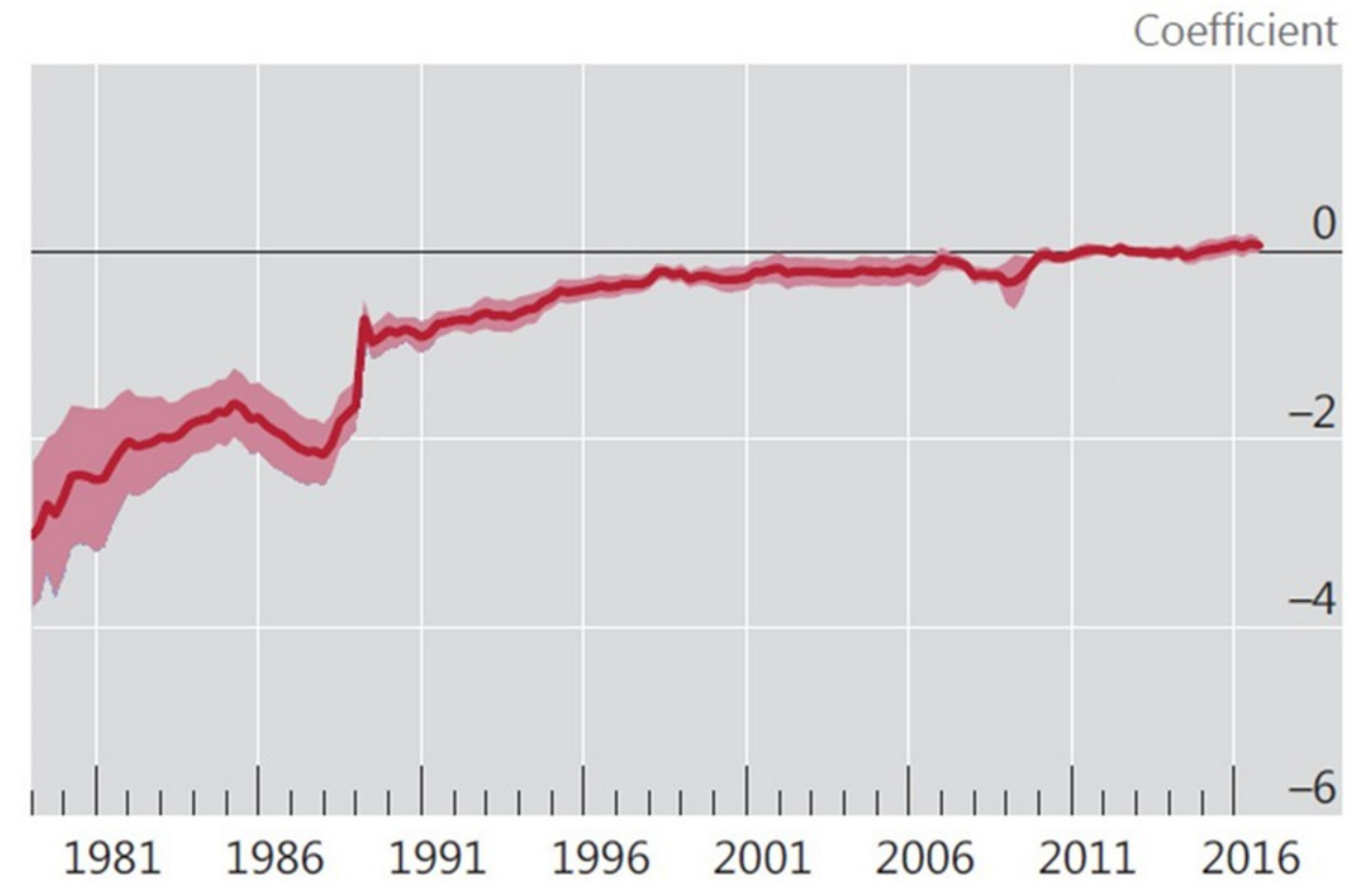

Source: Bank for International Settlements (2017).

Note: Rolling 15-year window estimates and confidence bands from a panel of G-7 economies. 


\section{U.S. evidence}

- Another way to see this same idea, but for U.S. data only, is to consider the chart used by Chairman Powell in a recent speech.*

- This analysis uses annual U.S. data with 20-year rolling windows.

- Inflation is measured as core personal consumption expenditures (PCE) inflation.

- Labor market slack is measured by the unemployment gap, that is, deviations of the unemployment rate from the Congressional Budget Office estimate of the natural rate.

- The chart plots the negative of the Phillips curve slope, and again, its value tends toward zero in more recent data.

* See Figure 5 in J.H. Powell, "Monetary Policy and Risk Management at a Time of Low Inflation and Low

Unemployment," remarks delivered at the 60 th Annual NABE Meeting "Revolution or Evolution? Reexamining Economic Paradigms," Boston, Mass., Oct. 2, 2018. 


\section{Phillips curve slope in the U.S.}

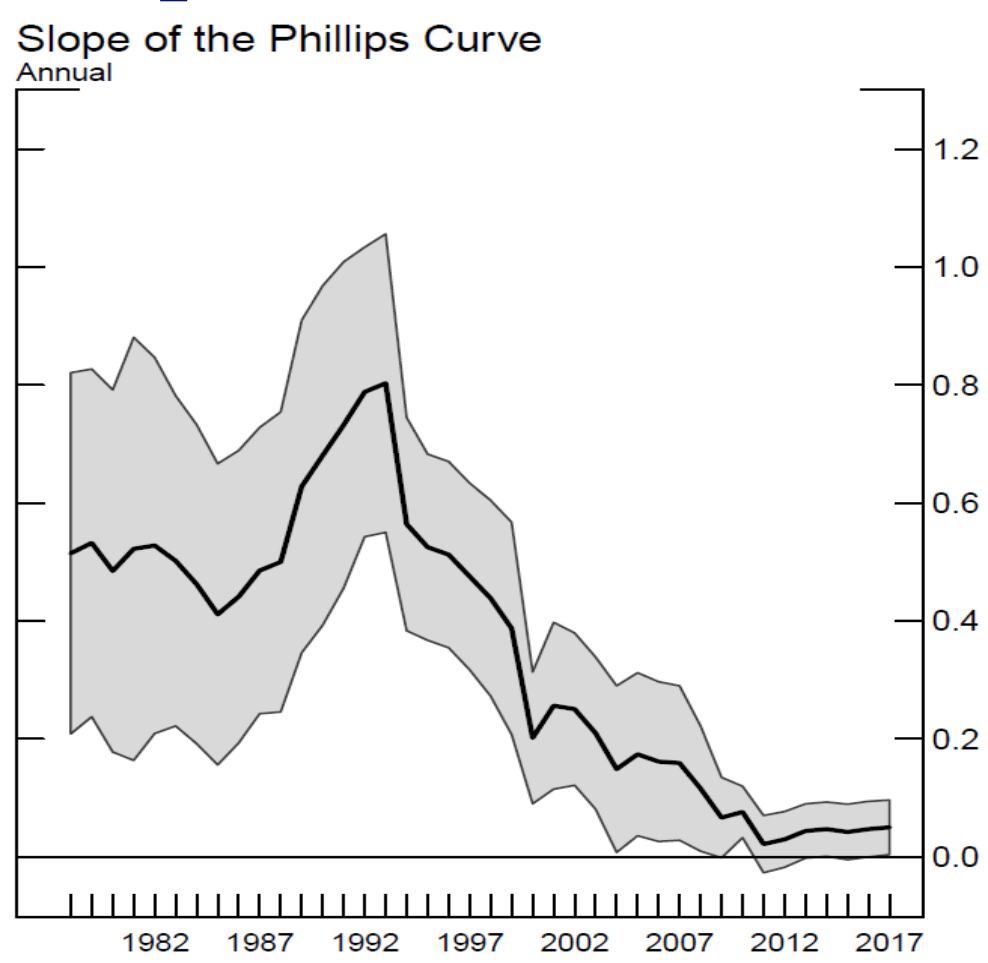

Source: J.H. Powell (2018). Last observation: 2017.

Note: Rolling 20-year window estimates and confidence bands; negative of the Phillips curve slope portrayed. 


\section{Attenuated feedback}

- The chart based on U.S. data indicates that the feedback from the real economy to inflation has attenuated significantly in recent years.

- Based on the chart, we might infer that the degree of attenuation has been approximately a factor of 10 ; that is, an unemployment gap that would have generated 100 basis points of inflation in the past would today generate only about 10 basis points of inflation.

- To capture this attenuation, the coefficient adjusting for this effect in the monetary policy rule, $\phi_{y}$, can be reduced by a factor of 10 . That is, instead of $\phi_{y}=1$, set $\phi_{y}=0.1$.

- I will make this adjustment as well in the modernized policy rule. 


\section{Better Measures of Inflation Expectations}




\section{Real-time inflation expectations}

- I have so far made two adjustments to modernize the monetary policy rule.

- There is one more adjustment to make regarding inflation.

- In the 1980s and 1990s, there was no market for Treasury inflation protected securities (TIPS), and consequently there were no reliable realtime estimates of inflation expectations.

- However, we now have about two decades' worth of data on inflation compensation coming from these markets, and these data provide an important guidepost for monetary policymakers. 


\section{Incorporating real-time inflation expectations}

- In the original monetary policy rule literature following Taylor, the "inflation gap" was typically measured as the distance between today's inflation rate and the inflation target.

- With today's real-time inflation expectations data, we can change the inflation gap term to measure the distance between the market-based expectations of inflation over the next five years and the inflation target.

- Because the TIPS data are based on consumer price index (CPI) inflation, I subtract 30 basis points to make this expectations measure more closely correspond to the FOMC's preferred measure of inflation, which is PCE inflation. 


\section{Advantages of real-time inflation expectations}

- One advantage of using inflation expectations in a modernized policy rule is that it allows for a forward-looking element in the rule.

- Forward-looking financial market participants are incorporating all available information - including existing theories, market developments and other policy developments - in forming their expectations of future inflation.

- Other adjustments can be made to TIPS data, but here I use a straight read of the data as inflation expectations. 


\title{
Real-time inflation expectations are low
}

\author{
Market-Based Inflation Expectations \\ Percent \\ with a CPI-to-PCE Adjustment
}

2.5

2 percent inflation target

2.0

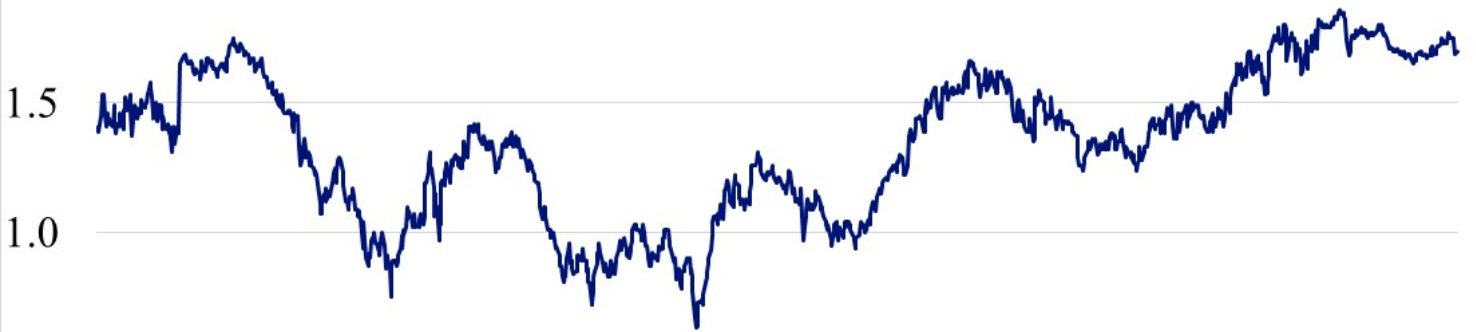

0.5

-5-Year Breakeven Inflation Rate Minus 30 bps.

0.0
Jan-14 Jan-15 Jan-16 Jan-17 Jan-18

Sources: Federal Reserve Board and author's calculations. Last observation: Oct. 15, 2018. 


\section{The message from inflation expectations}

- The current reading on market-based inflation expectations shown in the chart suggests that financial markets do not expect the Fed to attain its stated inflation target over the next five years on a PCE inflation basis.

- I will incorporate an expected inflation gap in the modernized version of the monetary policy rule.

- This completes the necessary adjustments to the policy rule, so let's now turn to the implications of modernization for current policy. 


\section{A Modernized Monetary Policy Rule}




\section{A modernized monetary policy rule}

- I have discussed three modernizing adjustments to the widely used benchmark Taylor (1999) rule.

- These adjustments are to use a lower value for the short-term real interest rate ("r-star"), attenuate the feedback parameter from the real economy to inflation by a factor of 10 and replace the inflation gap with an inflation expectations gap.

- The next chart plots the net effect of these three adjustments against the Summary of Economic Projections (SEP) median policy rate path and the policy rate path implied by the unmodernized Taylor (1999) rule given at the beginning of this talk. 


\section{Federal funds rate projections}

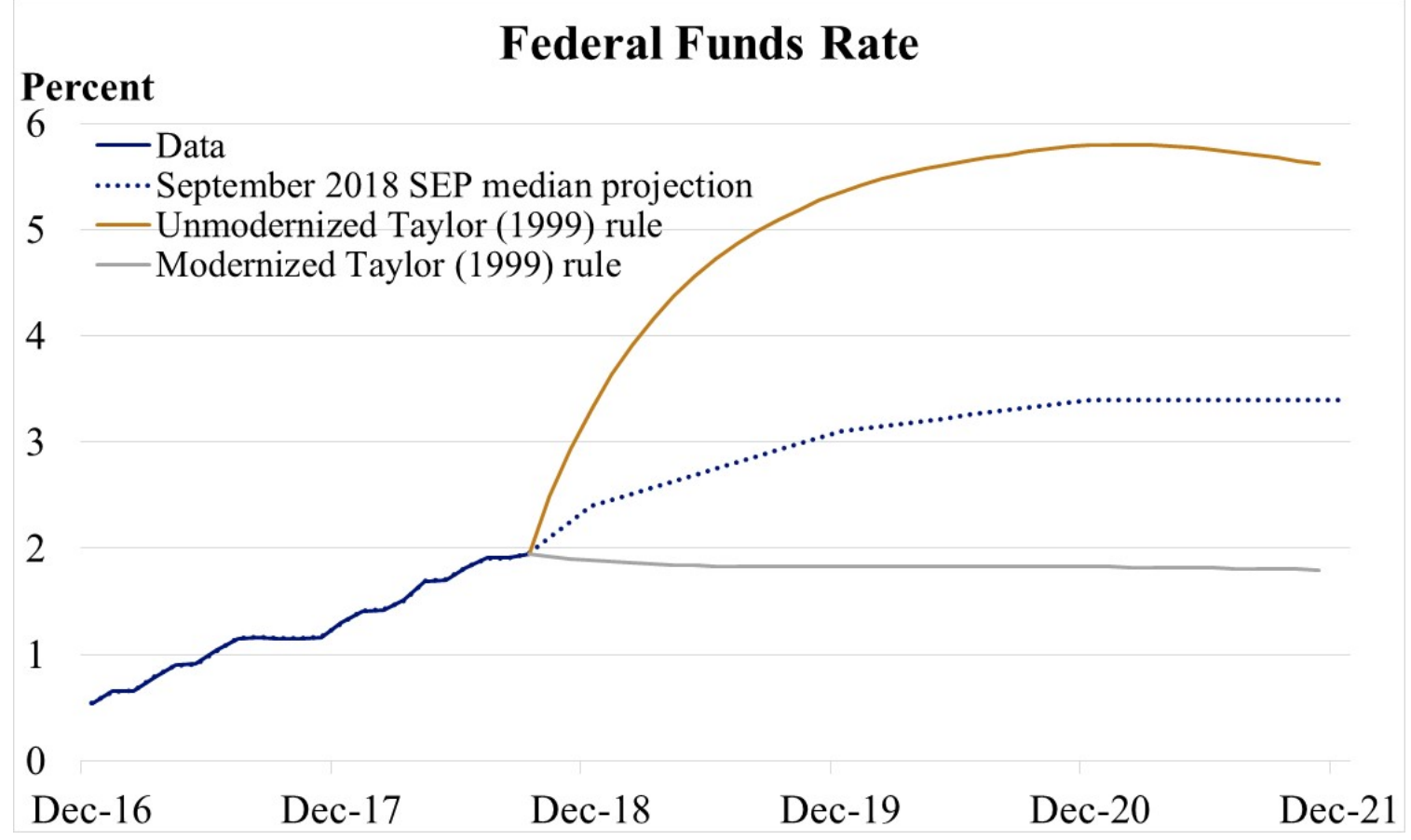

Sources: Federal Reserve Board and author's calculations. Last observation: September 2018. 


\section{A subdued policy rate path}

- The chart shows that the modernized version of the Taylor (1999) rule recommends a relatively subdued policy rate path over the forecast horizon - similar to the St. Louis Fed's recommended path in the SEP.

- The unmodernized Taylor (1999) rule calls for rapid increases in the policy rate, but this rule does not take into account the three important macroeconomic developments since the 1980s discussed in this talk.

- The FOMC's September 2018 median SEP path arguably takes on board some of the modernization discussed in this talk, and thus the projected policy rate path is between the modernized and unmodernized versions of Taylor (1999). 


\section{Conclusion}




\section{Conclusion}

- Monetary policy rules have proven to be very useful in laying out benchmarks for monetary policy actions, both in academic papers and in practical policymaking.

- One popular rule has been Taylor (1999), which was constructed based on U.S. data from the 1980s and 1990s.

- Since that time, three important macroeconomic developments have altered key elements of policy rule construction.

- Incorporating these developments yields a modernized Taylor (1999) policy rule that suggests maintaining the current level of the policy rate would be an appropriate policy over the forecast horizon. 


\section{Connect With Us}

FEDERAL RESERVE BANK of ST. LOUIS

\section{James Bullard}

stlouisfed.org/from-the-president

STLOUISFED.ORG

Federal Reserve

Economic Data (FRED)

Thousands of data

series, millions of users
Blogs and

Publications

News and views

about the economy

and the Fed
Economic

Education Resources

For every stage of life
Community Development Promoting financial stability of families, neighborhoods 